\title{
SIMONE WEIL: EL TRABAJO Y EL ESPÍRITU DE LA VERDAD
}

\section{SIMON WEIL: THE WORK AND THE SPIRIT OF FREEDOM}

Jaime Abad Montesinos ${ }^{1}$

Université Paris - VIII / Lycée Général et Technologique Talma, Brunoy (Francia)

Recibido: 15-1-2014

Aceptado: 15-3-2016

Resumen: El presente artículo quiere mostrar la estrecha relación y la importancia que tienen, en la obra de Simone Weil, las nociones de trabajo y de verdad. Lúcida testigo de los sucesos ocurridos en Europa en la primera mitad del siglo XX, su pensamiento supo desentrañar las raíces profundas de su tiempo, el vacío y las contradicciones de su época. La obra de Simone Weil representa una relectura del mundo marcada por la desgracia, en la que sobresale un anhelo de verdad íntimamente ligado al concepto de trabajo, en tanto que vínculo profundo del hombre con la realidad.

Palabras clave: trabajo, verdad, desgracia, arraigo.

\begin{abstract}
The current article aims to show the close relationship and the importance of the notion of work and truth in the work of Simone Weil. Lucid witness of the events happened in Europe during the first half of the twentieth century, her thought knew unravel the deep roots of her time, the emptiness and the contradictions of her epoch. Simone Weil's work represents a rereading of the world marked by her misfortune, in which a yearning for truth stands out closely linked to the concept of work, in so far as a deep link of the man with the reality.
\end{abstract}

Key words: work, truth, misfortune, deep-rooted.

1. (jaime-abad@hotmail.com) Licenciado en Filosofía por la Universitat de València. Máster en Pensamiento Filosófico Contemporáneo. Amplió sus estudios con una beca de investigación en la Université Toulouse II-Le Mirail durante el año 2011-2012. 
Pero la verdad es, como se ha mostrado, la unidad de ambos: la luz, que no brilla en la tiniebla, sino está compenetrada con ella como con la esencia, y precisamente por eso está sustanciada, materializada. La luz no brilla en la tiniebla, no la ilumina, no está refractada en ella, sino que es el concepto quebrado en sí mismo.

G. W. F. Hegel ${ }^{2}$

Deseamos la verdad y sólo encontramos en nosotros incertidumbre. Buscamos la felicidad y sólo encontramos miseria y muerte.

Blaise Pascal ${ }^{3}$

\section{Introducción}

Destacó Simone Weil en L'enracinement, considerado su testamento espiritual, que no todas las crueldades son físicas, pues algunas llegan más allá de la carne. Si bien existen ciertas crueldades fácilmente reconocibles dada su violencia, como es el caso de aquellas ejercidas sobre el cuerpo mismo de las poblaciones sometidas, existen otras crueldades más difusas, pero igualmente relevantes dentro de una sociedad: aquellas «que atentan contra la vida del hombre sin atentar contra su cuerpo» ${ }^{4}$. Ellas suponen la privación de alimentos necesarios para el alma del ser humano, alimentos que cohesionan colectividades, en tanto que son el sustento espiritual de los hombres que nacen en ellas, es decir, su vínculo con el pasado: el «arraigo» («l'enracinement») necesario para su alma. Igual que el cuerpo humano tiene necesidad de alimentos, de descanso y de calor, tiene el alma humana, para Simone Weil, necesidades que no debemos olvidar: honor, respeto, seguridad, etc.; puesto que, cuando éstas no son satisfechas, provocan que el alma se encuentre «en un estado análogo al

2. Hegel, G. W. F.: Filosofía Real. Madrid: FCE, 2006, p. 71.

3. Pascal, B.: Pensées. Paris: Gallimard, 2004, p. 240.

4. Weil, S: L'enracinement. Paris: Gallimard, 1990, p. 14.

Thémata. Revista de Filosofía $\mathrm{N}^{\circ} 54$ (2016) pp.: 11-32 
estado de un cuerpo hambriento y mutilado» ${ }^{5}$. Sin embargo, por encima de todas ellas existiría, para Weil, una sola: la necesidad de verdad ${ }^{6}$.

Comprometida desde muy joven con la causa de los oprimidos, su obra y su existencia, caracterizadas por una inicial militancia sindicalista de tendencias anarquizantes ${ }^{7}$, desembocarán en un sentimiento religioso muy personal, marcado por la espera y la gracia, pero crítico con los dogmas católicos, y con la propia institución eclesiástica ${ }^{8}$. Porque en la obra de Weil, mística y revolucionaria al mismo tiempo, contradictoria y alucinada, pero siempre honesta, un solo espíritu anima su pensamiento; por encima de dogmas religiosos, por encima de ideologías políticas, late un profundo deseo, como escribió Rimbaud, de "poseer la verdad en un alma y en un cuerpo»9. Este espíritu que atraviesa toda su obra es «el espíritu de verdad» ("l'esprit de vérité»), la fuerza de la verdad concebida como "energeia", en tanto que fuerza actuante inserta en el mundo mismo; es el deseo de realidad en su verdad esencial, cuya fuerza revierte necesariamente sobre la vida política. En palabras de Simone Weil: «el amor puro es esta fuerza actuante, el amor que no quiere bajo ningún concepto, en ningún caso, ni mentira ni error» ${ }^{10}$.

Verdad y política se unen estrechamente en la obra de Weil, como ha destacado Carmen Revilla ${ }^{11}$, articulándose como las dos perspectivas que orientarán, a lo largo de toda su vida, su actividad intelectual; una política marcada por un lucido análisis de la situación de su época y un compromiso con los más desfavorecidos, una verdad considerada como la más alta aspiración de todo ser humano. Es la obra filosófica de Weil, como han destacado todos sus comentaristas, pensamiento indisolublemente li-

\section{Weil, S: Escritos de Londres y últimas cartas. Madrid: Trotta, 2000, p. 68}

6. Así nos lo dice en L'enracinament: «La necesidad de verdad es más sagrada que ninguna otra» (Weil, S: L'enracinement, cit., p. 53).

7. Anota Weil en uno de sus cuadernos (Cahiers): «Considerar siempre a los hombres en el poder como cosas peligrosas» (Weil, S: Euvres complètes. Tome VI. Cahiers. Volume 1. (1933Septembre 1941). Paris, Gallimard, 1994, p. 87), «Estar frente a la naturaleza, no frente a los hombres; es la única disciplina. Depender de una voluntad extraña es ser esclavo (...). No se puede depender de los seres humanos sin aspirar a tiranizarlos» (Ibídem, p. 96). Sin embargo, su pensamiento, contradictorio y trágico, nunca será capaz de volcarse completamente en el sueño de un paraíso terrestre que rompa con toda esclavitud.

8. En los escritos de su ultima etapa una profunda tensión se deja ver entre su fe y el mensaje cristiano, tal y como éste ha sido institucionalizado por la Iglesia católica: «se puede afirmar sin temor de exageración que el espíritu de la verdad está casi ausente de la vida religiosa» (Weil, S: L'enracinement, cit. pp. 315-316).

9. Rimbaud, A.: Poésies. Une saison en enfer. Illuminations. Paris, Gallimard, 1993, p. 152.

10. Weil, S.: L'enracinement, cit., p. 320.

11. Revilla, C.: «Simone Weil: entre el poder de la fuerza y el poder de las palabras» en Archipiélago 43, 2000, Sep-Oct, p. 72. 
gado a su tiempo, profunda reflexión sustentada por su experiencia vital ${ }^{12}$ y marcada por el sufrimiento. Porque su filosofía pretende ser pensamiento encarnado, entrelazado con la necesidad que domina el universo que nos rodea: "pensamiento materialmente presente en nuestra carne» ${ }^{13}$, inmerso en el mundo donde habita nuestro cuerpo, pero caracterizado por la firme decisión «de vivir exclusivamente para la búsqueda de la verdad» ${ }^{14}$, un pensamiento llamado pues a alcanzar todos los planos de la existencia, por encima del sufrimiento y las privaciones, hasta el borde mismo de la muerte. Porque Simone Weil «nunca renunció a combatir los poderes opresivos; siempre se comprometió en esta lucha protagonizando empeños peligrosos e insólitos. Siempre persiguió obstinadamente la verdad, en los terrenos más diversos» ${ }^{15}$.

\section{Desarraigo}

Afirma Juan Ramón Capella ${ }^{16}$, en su presentación a la traducción española de L'enracinement, (Echar raíces), que enfrentarse a la lectura de dicha obra -podríamos extenderlo al conjunto de los escritos de Simone Weil-supone practicar un suerte de «minería», al proceder como un buscador de oro, que rastrea entre las palabras las proposiciones fundamentales de una de las reflexiones más profundas del pasado siglo, una de las miradas más puras y penetrantes del pensamiento europeo ${ }^{17}$.

Nacida en una familia judía acomodada y habiendo recibido una esmerada educación, desde muy joven siempre sintió Simone Weil que su sitio estaba con los desheredados, con los que sufren por siempre, desplazados en los bordes de las sociedades y la historia. En medio de una época atravesada por dos guerras mundiales y por el auge de los totalitarismos, su honestidad y su entrega extrema, rayando en ocasiones la sin razón ${ }^{18}$, le llevaría en todo momento a exigirse siempre a sí misma «adoptar la mejor

12. Cfr. Revilla, C.: «Al final de la tregua: verdades radicales en la obra de Simone Weil» en Anthropos 211, 2006, pp. 97-105.

13. Weil, S: L'enracinement, cit., p. 368.

14. Revilla, C: Simone Weil: entre el poder de la fuerza cit., p. 72.

15. Pétrement, S: Vida de Simone Weil. Madrid: Trotta, 1997, p. 331.

16. Weil, S: Echar raíces. Madrid: Trotta, 1996. Presentación de Juan Ramón Capella. Traducción de Juan Carlos González Pont y Juan Ramón Capella, p. 9.

17. Cfr. Esposito, R: «Simone Weil y Europa» en Archipiélago 43, 2000, Sep-Oct, pp. 37-44.

18. Conocida es la anécdota que afirma que el propio De Gaulle la tachó de "loca", cuando le comunicaron su proyecto de crear un cuerpo de enfermeras de primera línea que fuese lanzado en paracaídas en pleno campo de batalla (Cfr. Pétrement, S: op. cit., p. 696). 
actitud posible respecto de los problemas de este mundo» ${ }^{19}$. Lúcida testigo de algunos acontecimientos que sacudieron la primera mitad de siglo veinte, resulta sorprendente, tal y como ha remarcado Bertrand Saint-Ser$\operatorname{nin}^{20}$, que una joven profesora de filosofía de un lycée de provincias, en Le Puy, Auxerre o Roanne, haya tenido una intuición tan clara de algunos de los hechos que marcaron su tiempo; anticipando incluso los rasgos de una época aún naciente: la nuestra.

La sustitución de la era industrial por la era financiera reside esencialmente en que el factor decisivo del crecimiento de la empresa ya no es la capitalización del beneficio, sino la dominación de nuevos capitales - de ahí la desaparición de todo lo que había de favorable en una producción bien organizada. ${ }^{21}$

Resulta inevitable no sorprenderse al leer estas líneas escritas por Weil, anticipadoras de un tiempo donde la financiarización económica ha terminado por consolidarse a escala supranacional. Es inevitable igualmente establecer ciertos paralelismos, a pesar de todas las diferencias, entre nuestra actual época de crisis, acaparadora de portadas y titulares en todos los periódicos, y la crisis vivida en Europa cuando fueron escritas esas frases, y cuyas funestas consecuencias son de sobra conocidas. Ya nos advirtió Weil, hace más de medio siglo, que el dinero es un poderoso factor de desarraigo que atraviesa las sociedades dinamitándolas desde lo más hondo. Reclamando en todo momento nuestra atención completa y todas nuestras energías, "el dinero destruye las raíces por todas partes donde penetra, sustituyendo todas las motivaciones por el deseo de ganar» ${ }^{22}$. Si bien el dinero es comúnmente aceptado por una sociedad como medio de intercambio, abogará Weil por hacer desaparecer su valor psicológico, desacreditándolo con vistas a eliminar el rol de «juez y verdugo» ${ }^{23}$ que ha adquirido dentro de las sociedades contemporáneas ${ }^{24}$. Para que aquellos que no lo posean no se vean abocados inevitablemente al sufrimiento por su

19. Weil, S:A la espera de Dios. Madrid: Trotta, 1993, p. 38.

20. Saint-Sernin, B: «Simone Weil, critique de la société» en Étvdes 366, Fév., 1987, p. 239

21. Weil, S.: O.C. Tome VI. cit., p. 128.

22. Weil, S.: L'enracinement, cit., p. 63.

23. Weil, S.: Escritos, cit., p. 137.

24. En una carta enviada, junto con un poco de dinero, a un anarquista español llamado Antonio, recluido en un campo de internamiento, escribirá Weil: "Cuando tengo dinero en mis manos, nunca tengo la impresión de que ese dinero sea de mi propiedad. Está ahí, sencillamente (...). Simplemente pasa de mis manos a los de otra persona que lo necesita, como si yo no tuviera nada que ver en esto. Me gustaría que el dinero fuera como el agua y que corriera allí donde hace falta» (Pétrement, S.: op. cit., p. 587-588).

Thémata. Revista de Filosofía No54 (2016) pp.: 13-32. 
ausencia, para que los que lo posean no se olviden de las obligaciones que atañen a todo ser humano. Porque dichas obligaciones son la expresión directa de las necesidades del hombre, las cuales no reposan sobre ninguna convención social ni histórica, puesto que, para Weil:

Las necesidades del ser humano son sagradas. Su satisfacción no puede estar subordinada ni a la razón de Estado, ni a ninguna consideración, ya sea de dinero, de raza, de color, ni al valor moral u otro atribuido a la persona considerada, ni a ninguna condición, cualquiera que sea. ${ }^{25}$

El dinero supone un factor de desarraigo porque desplaza todo el centro de nuestra vida hacia él, borra todas nuestras necesidades y se convierte en único soberano de nuestra existencia. Convocando todas nuestras energías, teje un largo manto de sueño y de olvido en torno nuestro. Allí donde la posesión del dinero se convierte en cumbre social, el resto de nuestras necesidades queda en la noche. Ahora bien, si la obtención del salario mensual reclama toda nuestra atención, al mismo tiempo, trae consigo una economía del miedo, que asedia a los seres humanos durante los días y las noches ante la posibilidad de su pérdida.

Existirá, no obstante, un segundo factor de desarraigo para Weil: la educación institucional, producto "de una cultura considerablemente orientada hacia la técnica e influenciada por ella, muy teñida de pragmatismo, extremadamente fragmentada por la especialización» ${ }^{26}$. La educación, tal y como es entendida en la época contemporánea, pretende únicamente transmitir unos conocimientos al alumno para que juegue su rol en el futuro de forma competente. Pero por ello mismo, para Weil, le hace distanciarse de la región donde habita la verdad. La educación actual discrimina individuos, considerando a unos más inteligentes y a otros más inútiles; contribuyendo así a la degradante división entre trabajo manual y trabajo intelectual. La ciencia y el conocimiento se convierten entonces en monopolios de un determinado sector de la sociedad, "no a causa de una mala organización de la instrucción pública, sino por su naturaleza misma ${ }^{27}$, cuyo fundamento esencial es la especialización del saber, en aras de la productividad. Si toda nuestra civilización reposa, en ultimo termino, sobre la especialización, entonces la tendencia a la opresión parece inevitable, dado «el sometimiento de aquellos que ejecutan a quienes

25. Weil, S.: Escritos, cit., p. 68.

26. Weil, S: L'enracinement, cit., p. 64.

27. Weil, S. «Réflexions sur les causes de la liberté et de l'oppression sociale» en Oppression et liberté Paris: Gallimard, 1967, p. 62. 
coordinan ${ }^{28}$. Es este desequilibrio el factor social que traza el limite de imposibilidad de todo reconocimiento en términos de igualdad, la opresión que se expresa con conceptos de ciencia atravesada de exclusión, al negar a una parte de la sociedad el acceso al conocimiento: el acceso, en definitiva, a la verdad. Sin embargo, para Weil:

Un idiota de pueblo, en el sentido literal de la palabra, que ama realmente la verdad, aun cuando tan solo emitiera balbuceos, es en cuanto al pensamiento infinitamente superior a Aristóteles. Está infinitamente más próximo a Platón de lo que Aristóteles ha estado nunca (...). Pero de todo eso no sabe nada. Nadie se lo ha dicho. Todo el mundo le dice lo contrario. Hay que decírselo. ${ }^{29}$

Porque si el ser humano tiene necesidad de arraigo entonces la exclusión es intolerable, y promoverla en cualquiera de sus formas debe ser considerado un crimen ${ }^{30}$. Negarle su derecho al trabajo, negarle su dignidad al discriminarle por sus capacidades, excluirle en función de su poca capacidad en términos académicos,... todo ello significa atentar contra las raíces del ser humano. Porque sólo puede haber arraigo allí donde el hombre vive en la verdad, donde reinan la justicia, la fraternidad, la libertad. Cuando se niegan esas aspiraciones los cimientos de una sociedad se tambalean, y entonces lo que tenemos es crisis, y sabemos bien que no todas las crisis son económicas, algunas golpean lo más profundo del alma, como Weil no cesó en destacar en toda su obra. Escribió María Zambrano que «vivir en crisis es vivir en inquietud» ${ }^{31}$, dado que, aunque se anhele con vehemencia el sosiego a lo largo de la vida, una infinita inquietud no cesa de golpearnos, amenazando con devorar nuestra existencia completamente. Según Zambrano, «la crisis muestra las entrañas de la vida humana, el desamparo del hombre que se ha quedado sin asidero, sin punto de referencia; de una vida que no fluye hacia meta alguna y que no encuentra justificación ${ }^{32}$ : una vida, en definitiva, desarraigada, perdida. Sin embargo, la noción de desarraigo en Simone Weil no nos remite exclusivamente a la angustia existencial, al estado de inquietud de la persona para quien la vida ha perdido todo horizonte; sino que nos remite igualmente a la con-

28. Ibídem, p. 63.

29. Weil S: Escritos, cit., p. 137.

30. Cfr. Ibídem, p. 70.

31. Zambrano, M: Hacia un saber del alma. Madrid. Alianza Editorial, 2005, p. 100.

32. Ibídem, p. 101-102.

Thémata. Revista de Filosofía No54 (2016) pp.: 13-32. 
dición social de todo ser humano, en tanto que individuo inmerso en una serie de prácticas sociales y definido por su relación con el trabajo.

Jugará éste último un papel esencial a lo largo de toda la obra weiliana, en tanto que es la forma propiamente humana de relacionarse con el mundo, pero que, dada la situación contemporánea, exige ser reformulada con urgencia. Porque el trabajo dejó hace mucho tiempo de ser soñado como espacio donde la verdad y la belleza del mundo se hacen patentes, para pasar a ser experimentado como lugar de opresión y de miseria. La consecuencia inevitable de tal situación de deshumanización y de inseguridad siempre latente es la descomposición de la vida social, la condena insalvable al desarraigo. Según expone Weil en una de sus obras más importantes, Reflexiones sobre las causas de la libertad y de la opresión social:

Podemos preguntarnos si existe un ámbito de la vida pública o privada en que las fuentes mismas de la actividad y de la esperanza no estén envenenadas por las condiciones en las que vivimos. El trabajo ya no se realiza con la conciencia orgullosa de ser útil, sino con el sentimiento humillante y angustioso de poseer un privilegio otorgado por un golpe de suerte pasajero, en pocas palabras, de poseer un puesto de trabajo, un privilegio del cual se excluye a muchos seres humanos por el hecho mismo de que uno goza de él. ${ }^{33}$

\section{Trabajo}

Aunque en una parte de las obras dedicadas a Simone Weil los elementos biográficos -especialmente en sus aspectos más trágicos y sorprendentes- han primado por encima de la profundidad de sus escritos, no hemos de olvidar que, como ya señaló Miklos Vetö, «alguien que ignore las circunstancias de su vida no tiene ninguna oportunidad de comprender verdaderamente el pensamiento de Simone Weil $»^{34}$. No han cesado de destacar todos los lectores de Weil la profunda conexión entre su vida y sus escritos, su firme convicción de que no hubiese ninguna separación «entre lo que uno piensa y la vida que uno lleva» ${ }^{35}$. Es precisamente esa convicción la que le hará solicitar una baja como profesora de filosofía, con el objetivo de trabajar en una fábrica, y conocer directamente los mecanismos de la opresión ejercida sobre los trabajadores; pasando así a completar las reflexiones teóricas viviéndolas en carne propia. Aunque la experiencia

33. Weil, S. «Réflexions» cit., p. 57.

34. Vetö, M.: La métaphysique religieuse de Simone Weil. Paris: J. Vrin, 1971, p. 10.

35. Pétrement, S.: op. cit., p. 86.

Thémata. Revista de Filosofía $\mathrm{N}^{\circ} 54$ (2016) pp.: 11-32 
de la fábrica no resultó lo que ella esperaba, según apunta Simone Pétrement, la afectó tan profundamente que supuso un antes y un después en su vida ${ }^{36}$. Tal y como afirmará Simone Weil en una carta a Albertine Thévenon: «hay una cierta ligereza de corazón que me será, me parece, para siempre imposible» ${ }^{37}$.

Fueron los años pasados en Le Puy, así como en Auxerre o Roanne, una etapa no sólo dedicada a la docencia académica sino también de intensa militancia política y de compromiso social. Será concretamente en Le Puy, donde entrará en contacto con los medios sindicalistas revolucionarios, colaborando en publicaciones como La Révolution Proletarienne, impartiendo cursos sobre marxismo en la Bourse du Travail de Saint-Etienne o participando en manifestaciones de parados y en diversos actos sindicales. Siempre conmovida ante las injusticias sociales y empujada por un firme deseo de integración con la causa obrera, pero también contraria a todo autoritarismo intelectual, crecerá progresivamente en Simone Weil, una profunda desconfianza respecto de los sindicatos -dada la creciente burocratización de estos-, al igual que respecto del dogmatismo ideológico que el sindicalismo revolucionario, a sus ojos, va adoptando de forma imparable. Todo ello le llevará a un progresivo distanciamiento del movimiento sindicalista, como expone en una carta enviada a uno de los líderes sindicales de Saint-Etienne: «Me asfixio en este movimiento revolucionario de ojos vendados», ${ }^{38}$ le escribirá Weil.

Uno de los factores de dicho distanciamiento es el firme compromiso de rechazo a toda doctrina que separe la teoría de la realidad, la verdad de la vida. Una teoría sólo puede ser válida, para Weil, en la medida en que está íntimamente ligada con la realidad y es capaz de desplazarse «entre las verdades eternas inscritas en la naturaleza de las cosas $»^{39}$. Hablar sobre la opresión y sobre los mecanismos con que ella se ejerce sobre la clase trabajadora implica entonces conocer dichos mecanismos directamente,

36. «La época de la fábrica fue el comienzo de un periodo menos feliz, mas sombrío y, al mismo tiempo, el periodo de una evolución intelectual o espiritual. Parece que no encontró en esta experiencia lo que buscaba: el descubrimiento de los métodos que permitirán transformar realmente la condición proletaria. Pero la experiencia tuvo sobre ella un efecto profundo y que no esperaba. Produjo una modificación de sus sentimientos y poco a poco de sus pensamientos, una modificación inesperada en efecto para ella» (Pétrement, S.: op. cit., p. 333).

37. Weil, S.: La condition ouvrière. Paris: Gallimard, 1951, p. 15.

38. Pétrement, S.: op. cit., p. 239.

39. Weil, S.: L'enracinement, cit., p. 277.

Thémata. Revista de Filosofía No54 (2016) pp.: 13-32. 
vivir la teoría ${ }^{40}$ más allá de los medios académicos, experimentando los sufrimientos sobre la propia carne, hasta tener, como ella afirmará: «el cuerpo vacío de toda energía vital, el espíritu vacío de pensamiento, el corazón inundado de asco, de rabia muda y, por encima de todo esto, de un sentimiento de impotencia y de sumisión $»^{41}$. Expone Weil, años después, sobre esa experiencia vivida como obrera, en una carta dirigida al Padre Perrin, que:

Tenía el alma y el cuerpo hechos pedazos; el contacto con la desdicha [malheur] había matado mi juventud. Hasta entonces, no había tenido experiencia de la desdicha, salvo la mía, que, por ser mía, me parecía de escasa importancia y que no era, por otra parte, sino una desdicha a medias, puesto que era biológica y no social. Sabía muy bien que había mucha desdicha en el mundo, estaba obsesionada con ella, pero nunca la había constatado mediante un contacto prolongado. Estando en la fábrica, confundida a los ojos de todos, incluso a mis propios ojos, con la masa anónima, la desdicha de los otros entró en mi carne y en mi alma. Nada me separaba de ella, pues había olvidado realmente mi pasado y no esperaba ningún futuro, pudiendo difícilmente imaginar la posibilidad de sobrevivir a aquellas fatigas. Lo que allí sufrí me marcó de tal forma que, todavía hoy, cuando un ser humano quienquiera que sea y en no importa qué circunstancia, me habla sin brutalidad, no puedo evitar la impresión de que debe haber un error y que el error va desgraciadamente a disiparse. He recibido para siempre la marca de la esclavitud [...]. Desde entonces, me he considerado siempre una esclava. ${ }^{42}$

La experiencia en la fábrica supondrá para Weil la toma de conciencia de la desgracia humana (le malheur), «que es a la vez dolor físico, angustia del alma y degradación social $»^{43}$ : el desvelamiento de la esencia misma de la condición obrera como experiencia desnuda de la esclavitud. Ahora bien, dos factores serán esenciales para hablar de esclavitud en el medio industrial: la velocidad en el ritmo de producción y las órdenes recibidas. El primero impone una cadencia en el lugar de trabajo que no deja espacio para el pensamiento y la reflexión, únicamente para la repetición mecánica de acciones desarrolladas con vistas a la productividad; el segundo, complementando al primero, impone una ética del silencio y

40. Tal y como expone Albertine Thévenon en el Avant-propos a La condition ouvrière: «Su extraordinaria inteligencia y su cultura filosófica le permitieron un conocimiento rápido y profundo de los grandes teóricos socialistas, en particular de Marx. Pero este conocimiento teórico de la explotación capitalista y de la condición obrera no le satisfacía. Consideraba útil penetrar en la vida de todos los días de los trabajadores». (Weil, S.: La condition, cit., p. 8)

41. Ibídem, p. 162.

42. Weil, S.: A la espera, cit. p. 40.

43. Ibídem, p. 85.

Thémata. Revista de Filosofía No54 (2016) pp.: 11-32 
de la obediencia ilimitada ${ }^{44}$, allí donde no cabe una voz que hable de cambio. La vida en la fábrica le enseñará a Simone Weil que, para quien ha sido condenado a trabajar durante horas, hasta quebrar su cuerpo y su alma como si fuese un esclavo, únicamente le queda aceptar su destino con docilidad ${ }^{45}$. Sin embargo, esta esclavitud en el medio industrial contemporáneo trae aparejada una opresión de nuevo cuño, de la que ya era consciente antes de incorporarse al mundo industrial, dados sus contactos con el mundo sindical en Le Puy. Frente a las sociedades tradicionales, donde la esclavitud se asocia al sometimiento mediante la fuerza de una parte de la sociedad, las sociedades capitalistas, como ya expuso Marx, trajeron consigo un sistema de opresión ejercido sobre aquellos que únicamente tienen su fuerza de trabajo para venderla a cambio de un salario. No obstante, la hipótesis propuesta por Weil, en el importante artículo de 1933: Perspectives. Allons-nous vers la révolution prolétarienne? ${ }^{46}$, es que un nuevo tipo de opresión comienza a consolidarse en las primeras décadas del siglo veinte, «la opresión ejercida en nombre de la función» ${ }^{47}$ : aquella que opone en la sociedad al personal cualificado y al no cualificado, a los trabajadores que se sirven de las maquinas en sus puestos de trabajo, frente a aquellos que son dominados por ellas. Esto es consecuencia inevitable de una sociedad que establece una división entre trabajo intelectual y trabajo manual, gracias, en primer lugar, a la formación, como ya hemos señalado anteriormente, pero también debido a la mecanización de los medios de producción. Entre ambos espacios, cualificado y no cualificado, «la máquina misma constituye una barrera infranqueable» ${ }^{48}$, es el limite de la esclavitud en un mundo cada día más tecnificado. Pero, aunque Weil es igual de consciente que Marx de la existencia de unos mecanismos de represión que la clase dominante dirige sobre la clase dominada, para ella estos no son sino consecuencia inevitable de tal distinción, dado que:

Toda nuestra civilización está fundada sobre la especialización, la cual implica el sometimiento de aquellos que ejecutan a quienes coordinan, y sobre tal base, únicamente se puede organizar y perfeccionar la opresión, pero no aligerarla. ${ }^{49}$

44. Cfr. Weil, S.: La condition, cit., p. 21.

45. En palabras de Weil: «Una docilidad de bestia de carga resignada. Me parecía que había nacido para esperar, para recibir, para ejecutar órdenes - que yo no había hecho nunca más que esto - que yo haría nunca más que esto» (Ibídem, p. 20-21)

46. Weil, S.: «Perspectives. Allons-nous vers la révolution prolétarienne?» en Oppression et liberté. Paris: Gallimard, 1967, pp. 9-38.

47. Ibídem, p. 21.

48. Weil, S.: «Perspectives» cit., p. 23.

49. Weil, S.: «Réflexions» cit., p. 63.

Thémata. Revista de Filosofía $\mathrm{N}^{\circ} 54$ (2016) pp.: 13-32. 
No obstante, si es indudable que existe la opresión «en tanto que órgano de una función social» ${ }^{50}$, es decir, como instrumento para el desarrollo de las fuerzas productivas, también es cierto que, para Weil, nada puede impedir que, en el fondo de nuestra alma, nos sintamos nacidos para la libertad ${ }^{51}$. Pero entendiendo libertad no como supresión de las leyes de la necesidad, puesto que tal concepción de la libertad no podría existir, ya que el hombre habita el mundo, y está sometido necesariamente a las leyes del universo; sino libertad para pensar por uno mismo y actuar conforme al orden del mundo: «un hombre será completamente esclavo si todos sus gestos proceden de otra fuente que su pensamiento, a saber, o bien las reacciones irracionales del cuerpo, o bien el pensamiento de otro» ${ }^{52}$. Lejos de ser un espacio de sometimiento forzado, el trabajo debe ser un acto libre, mediante el cual el hombre actúa metódicamente y recrea el mundo dado.

Si ocupa el trabajo, en la filosofía weiliana, un lugar central, es debido a que él es la forma en la que nos relacionamos con el mundo que nos rodea: el contacto real con la naturaleza, así como el acto de obediencia y de respeto ante la realidad de este mundo que es la necesidad. Es el trabajo, para Weil, sereno equilibrio entre el orden y la libertad: lugar espiritual donde se hace presente la verdad, llamado a hacer posible la escucha del silencio del mundo. Por todo ello, tal y como expone en L'enracinament, el trabajo debe transformase hasta convertirse en "centro espiritual $»^{53}$ de la vida humana, recuperando el espacio que la mecanización y la especialización le han negado. No es de extrañar pues todos los esfuerzos de Weil -algunos un tanto ingenuos- destinados a desarrollar un equilibrio entre la producción y los derechos de los trabajadores, proponiendo un nuevo régimen industrial implantado en el seno de cada empresa ${ }^{54}$, que permitiese a la clase trabajadora fortalecer sus conquistas espirituales y asegurar el reconocimiento de su dignidad, e hiciese posible la toma de conciencia de su responsabilidad en el proceso productivo. Ello permitiría, supuestamente, despertar en los trabajadores un sentimiento de vinculación con el fruto de su trabajo y con la producción en general, más allá de la preocupación obsesiva por el salario ${ }^{55}$, al permitirles, en todo momento, hacer uso de las

50. Ibídem, p. 81.

51. Cfr. Ibídem, p. 113.

52. Ibídem, p. 116.

53. Weil, S: L'enracinement, cit., p. 380.

54. Cfr. Weil, S.: «Principes d'un projet pour un régime intérieur nouveau dans les entreprises industrielles» en La condition ouvrière. Paris: Gallimard, 1951, pp. 207-213.

55. Cfr. Ibídem, pp. 208-209.

Thémata. Revista de Filosofía $\mathrm{N}^{\circ} 54$ (2016) pp.: 11-32 
facultades aprendidas, atendiendo a sus iniciativas sin degradarlos, ni menospreciarlos, sino todo lo contrario ${ }^{56}$, respetando su trabajo y su persona.

No obstante afirma Weil, «en cada hombre hay algo sagrado. Pero no es su persona. Tampoco es la persona humana. Es él, ese hombre, simplemente ${ }^{57}$. Aunque el lenguaje se queda mudo a la hora de definir el respeto que merece toda persona humana, no podemos no tener en cuenta la legitima aspiración de todo ser humano a que se le haga el bien, aspiración que en ocasiones adopta la forma de un grito, bajo los golpes y la esclavitud. No es de extrañar, igualmente, la firme propuesta de Weil de destruir toda separación entre trabajadores cualificados y no cualificados, «queremos hacer hombres completos al suprimir esta especialización que nos mutila a todos» ${ }^{58}$. Para la filosofía weiliana solamente borrando precisamente la división entre trabajo intelectual y trabajo manual podríamos reconvertir un espacio de opresión en un espacio de libertad, allí donde se lleve a cabo la perfecta unión de la libertad y la necesidad. Y ello pasa necesariamente por la formación intelectual de la clase trabajadora, pero, ante todo, por el respeto a todo ser humano y a las obligaciones que nos atañen como tales, así como por el reconocimiento de la dignidad que reside en el trabajo, sea cual sea su modalidad. Porque, para Weil:

Exactamente en la misma medida que el arte y la ciencia, aunque de manera diferente, el trabajo físico es un cierto contacto con la realidad, la verdad, la belleza de este universo, y con la sabiduría eterna de su disposición. Por ello envilecer el trabajo es un sacrilegio. ${ }^{59}$

Como ya muestra en sus Cahiers, fue consciente Weil desde muy pronto, que la verdadera revolución no será tal mientras se limite a un mero cambio político-económico ${ }^{60}$. Su experiencia industrial le confirmará la idea de que la verdadera revolución debe llegar más hondo. No debe pasar únicamente por una apropiación de los medios de producción por parte de los trabajadores, sino por un auténtico cambio en todos los ámbitos de la vida, donde el hombre no se vea sometido a la máquina, sino que haga uso

56. «Es preciso darles el sentimiento de colaborar en una obra, darles la noción de coordinación de los trabajos [...]. Será bueno igualmente dar cuenta a los obreros de todas las innovaciones, nuevas fabricaciones, cambios de método, perfeccionamientos técnicos. Es preciso darles el sentimiento de que la empresa vive, y de que ellos participan en esta vida» (Ibídem, p. 212).

57. Weil, S.: Escritos cit., p. 17.

58. Weil, S.: «Perspectives» cit., p. 32

59. Weil, S.: Escritos cit., p. 25.

60. «La revolución supone no simplemente una transformación económica y política, sino una transformación técnica y cultural» (Weil, S.: O.C. Tome VI Vol. 1 cit., p. 134).

Thémata. Revista de Filosofía $\mathrm{N}^{\circ} 54$ (2016) pp.: 13-32. 
de ella para «recrear lo que le es dado» ${ }^{61}$, donde se sienta libre para buscar la verdad en el mundo: aspiración última de toda persona que no puede ser negada.

\section{Verdad}

Escribió Paul Valéry que existen dos géneros de filósofos: los explicativos y los críticos, ambos marcados por dos defectos esenciales. El defecto de los primeros es hacer uso de más de lo necesario, el de los segundos ocultarse bajo un aparente rigor lingüístico. Existiría, no obstante, un tercer género minoritario para Valéry: el de aquel filósofo "casi místico»" ${ }^{62}$, que, tendiendo a sustituir la explicación por la identificación, "pretende sentir el mundo» ${ }^{63}$. Mucho se ha escrito sobre el complejo misticismo de Simone Weil, su profunda pero atormentada fe, así como la tensión existente entre ella y la ortodoxia cristiana. Si la obra de Weil en su última etapa no puede apartar la mirada de Dios, es la suya una creencia sin Iglesia ni dogmas, marcada por una honda creencia; pero incapaz de renunciar a la libertad de pensamiento, incapaz de aceptar, por ello, el dogmatismo intelectual católico que se expresa al decir anathema sit. "Permanezco junto a todas las cosas que no pueden entrar en la Iglesia, receptáculo universal, a causa de esas dos palabras» ${ }^{64}$; demasiados pensamientos quedarían excluidos tras ellas, demasiados saberes, demasiados seres humanos ${ }^{65}$.

$\mathrm{Su}$ biografía nos muestra una persona sensible, profundamente identificada con los sufrimientos ajenos, hasta el punto de sentirlos como propios, movida siempre por el sincero deseo de compartir su suerte con todos los excluidos, de sentir todo el pesar del mundo. Pero también nos muestra una persona que no puede dejar de mirar con los ojos del alma y amar la belleza armónica del mundo, un armonía que se expresa en términos de justicia, orden, belleza y, ante todo, verdad; dado que sentimos

61. Ibídem, p. 116.

62. Valéry, P.: Cahiers. Volume I. Paris: Gallimard, 1973, p. 553

63. Idem.

64. Weil, S.: A la espera cit., p. 46.

65. Como ella misma escribirá: «Tantas cosas están fuera de él, tantas cosas que amo y que no quiero abandonar, tantas cosas que Dios ama, puesto que de lo contrario no tendrían existencia... Toda la inmensidad de los siglos pasados a excepción de los veinte últimos, todos los países habitados por razas de color, toda la vida profana en los países de raza blanca y, en su historia, todas las tradiciones acusadas de herejía, como la maniquea y la albigense, todas las cosas surgidas del Renacimiento, muy a menudo degradadas, pero en absoluto carentes de valor» (Ibídem., p. 45). 
tras todo ello «la presencia de algo análogo a la sabiduría que querríamos poseer para saciar nuestro deseo de bien $»^{66}$.

Porque es la filosofía de Weil, en todo momento, serena aspiración a la verdad enfrentada al tiempo trágico que le tocó vivir, esfuerzo intelectual inclinado a desvelar todas las capas de la realidad, llevado hasta el limite de las fuerzas de un cuerpo, el cual terminaría por apagarse un día de agosto de 1943. En una carta enviada al Padre Perrin escribe Weil:

\begin{abstract}
A los catorce años caí en una de esas situaciones de desesperanza sin fondo de la adolescencia y pensé seriamente en morir a causa de la mediocridad de mis facultades naturales. Las dotes extraordinarias de mi hermano, que tuvo una infancia y una juventud comparables a las de Pascal, me forzaron a tomar conciencia de ellas. No lamentaba los éxitos externos, sino el no poder abrigar esperanzas de acceso a ese reino trascendente, reservado a los hombres auténticamente grandes, en el que habita la verdad. Prefería morir a vivir sin ella. Tras meses de tinieblas interiores, tuve de repente y para siempre la certeza que cualquier ser humano, aun cuando sus facultades naturales fuesen casi nulas, podía entrar en ese reino de verdad reservado al genio, a condición tan sólo de desear la verdad y hacer un continuo esfuerzo de atención por alcanzarla. ${ }^{67}$
\end{abstract}

Es la verdad, para Weil, «el esplendor de la realidad» («l'éclat de la réalitén) $)^{68}$, que se manifiesta ante los ojos del trabajador consciente y humilde en su jornada de trabajo, cuando éste no se ve impelido a trabajar de forma forzada. Y desear la verdad no es sino desear la realidad, ella es por tanto amor del mundo en todos sus facetas ${ }^{69}$, deseo de vida en la alegría y la desgracia ${ }^{70}$. «En lugar de hablar de amor a la verdad, es mejor hablar de un espíritu de la verdad en el amor» ${ }^{71}$ escribirá Weil en L'enracinement. Pero para que dicho espíritu exista en preciso que se arraigue. Tiene necesidad de calor de vida y de realidad, pero también de serenidad. La verdad necesita pues del trabajo y del cuerpo, necesita de vida social, pero también momentos de silencio y soledad, destinados a escuchar con atención, dado que «el tránsito a lo impersonal sólo se opera mediante

66. Weil, S.: L'enracinement cit., p. 19

67. Weil, S.: A la espera cit., pp. 38-39

68. Weil, S.: L'enracinement cit., p. 319

69. «Desear la verdad, es desear un contacto directo con la realidad. Desear un contacto con la realidad, es amarla. No deseamos la verdad sino para amar en la verdad. Deseamos conocer la verdad de lo que se amar» (Idem).

70. «Se sabe entonces que la alegría es la dulzura del contacto con el amor de Dios, que la desdicha es la herida de este mismo contacto cuando es doloroso y que lo único importante es el contacto, no la modalidad» (Weil, S.: A la espera cit., p. 56)

71. Weil, S.: L'enracinement cit., p. 319

Thémata. Revista de Filosofía No54 (2016) pp.: 13-32. 
una atención de una cualidad rara y que sólo es posible en soledad» ${ }^{72}$. Si el trabajo debe ser considerado según Weil el centro espiritual de la vida humana es debido a que él es la vinculación directa del hombre con su mundo y sus semejantes, es el espacio de enraizamiento del ser humano en el mundo y, al mismo tiempo, espacio de completo anonadamiento y humillación del alma, donde se reconcilia el pensamiento y la acción, y se desarrolla la virtud de la atención ${ }^{73}$. Es por el trabajo hasta el agotamiento como se prepara el alma en la filosofía weiliana para recibir "el espíritu de verdad", como aceptación humilde de la necesidad que tiende un puente en silencio hacia lo divino. Modelo de toda actividad humana, el trabajo permite al hombre entrar en contacto con el mundo y con todos los planos de la realidad, pero también gracias a él puede el hombre vaciar el alma, haciendo desaparecer todo lo subjetivo que hay en nosotros y abrirnos así a lo impersonal. Es el trabajo sereno intento de lectura y de interpretación del mundo, que exige silencio y atención, pero también esfuerzo y dedicación, dado que, para Weil:

El mundo es un texto con diferentes significados, y se pasa de un significado a otro por un trabajo. Un trabajo en el que el cuerpo siempre toma parte, como cuando aprendemos el alfabeto de una lengua extranjera, este alfabeto debe entrar en la mano a fuerza de trazar las letras. ${ }^{74}$

Hemos destacado que para Simone Weil en toda persona hay algo sagrado. Ahora bien, «lo que es sagrado, lejos de ser la persona, es lo que en un ser humano es impersonal» ${ }^{75}$, es precisamente esa exigencia de silencio lo sagrado que está más allá de nosotros, aquello que nos vincula con la verdad y la belleza, por medio del trabajo físico. Allí donde nuestra individualidad ha quedado disuelta queda abierto el espacio de lo impersonal, «la verdad y la belleza habitan ese dominio de las cosas impersonales y anónimas» ${ }^{76}$, su reino es soberano, y su apertura sólo es posible para un alma que presta atención. Cercana en este punto al Georges Bataille de $L a$ experiencia interior que ha afirmado: «el yo no importa nada» ${ }^{77}$, el espíritu

72. Weil, S.: Escritos cit., p. 21-22.

73. «Es por la atención como se sale de la cáscara de la autonomía, como nos alejamos de la perspectiva personal, [...]. Hacer el vacío en nosotros implica hacer el lleno en el mundo, pero esta salida de nosotros mismos sólo es verdaderamente extática si ella es permanente, es decir, cuando la atención se transforma en espera". (Vetö, M.: La métaphysique cit., p. 48).

74. Weil, S.: O.C. Tome VI. Vol. 1 cit., p. 295.

75. Weil, S.: Escritos cit., p. 20.

76. Ibídem, p. 21.

77. Bataille, G.: L'expérience intérieure. Paris: Gallimard, 2009, p. 64. 
de verdad de la filosofía weiliana exige «la destrucción del yo» ${ }^{78}$, la extrema renuncia de nuestra individualidad sacrificada en el vacío ante el altar de la gracia. La aniquilación de nuestro yo es la mayor entrega que puede hacer un hombre, puesto que es la renuncia al mayor acto de libertad que poseemos: la afirmación de nuestra propia subjetividad. Pero deja abierto al mismo tiempo el camino para la llegada de la gracia, y la redención por el dolor que se desarrolla con la destrucción del alma.

Afirma Durkheim en su obra Las formas elementales de la vida religiosa que en la mente del hombre la noción de lo sagrado está completamente alejada de la noción de lo profano, ambos representan dos espacios distantes separados por una «especie de vacío lógico» ${ }^{79}$, un límite que no puede ser franqueado por azar. Si algo han pretendido algunos de los escritos de la última etapa de Simone Weil es precisamente pensar ese vacío, su propia vida parece inclinarse hacia ese punto límite entre lo profano y lo sagrado, donde la desgracia amenaza con aniquilar el alma, y la vida misma se encuentra asediada por la posibilidad de su completa pérdida: «pensar eso con el alma entera es tener la experiencia de la nada» ${ }^{80}$, escribirá Weil al final de su vida. Pero este sentimiento de completa humillación del alma es condición indispensable para el tránsito hacia la región donde habita la verdad, "es una muerte del alma» ${ }^{81}$ atravesada por la desgracia, que se presenta en su pura desnudez, enmudeciendo nuestro espíritu. Como ya había expuesto Hegel en Prefacio a la Fenomenologia del espíritu, éste sólo da con la verdad de sí en su absoluto desgarramiento, cuando mira cara a cara a la muerte sin amedrentarse ${ }^{82}$. Asimismo, para Weil, sólo esperando atentamente la verdad en el vacío, con actitud humilde, y sin tratar de adivinar su contenido, es como ella llega a nosotros:

Pero los seres que a pesar de la carne y la sangre han franqueado interiormente un límite equivalente a la muerte reciben más allá otra vida, que no es en primer lugar vida, que es en primer lugar verdad. Verdad devenida viviente. Verdadera como la muerte y viviente como la vida. Un vida, como dicen los cuentos de Grimm, blanca como la nieve y roja como la sangre. Es ella el soplo de la verdad, el Espíritu divino. ${ }^{83}$

78. Weil, S.: La gravedad y la gracia. Madrid: Trotta, 1994, p. 75.

79. Durkheim, E.: Las formas elementales de la vida religiosa. Madrid: Alianza Editorial, 2003, p. 80.

80. Weil, S.: Escritos cit., p. 34.

81. Idem.

82. Cfr. Hegel, G. W. F.: Fenomenología del espíritu. Valencia: Pre-textos, 2009, p. 136

83. Weil, S.: L'enracinement cit., p. 314.

Thémata. Revista de Filosofía $\mathrm{N}^{\circ} 54$ (2016) pp.: 13-32. 


\section{Conclusión}

En una carta enviada a Maurice Schumann, apenas unas semanas antes de su muerte, escribe Weil: «para mí personalmente la vida no tiene otro sentido, y en el fondo jamás ha tenido otro sentido, que la espera de la verdad $\rangle^{84}$. Porque el discurrir de la filosofía de Weil revela en sus últimas etapas la certeza de que la verdad no se puede alcanzar, únicamente se la puede esperar, labrando el camino aguardando su llegada, y preparar así el alma en silencio y soledad para recibirla. El camino hacia la verdad es el camino de la renuncia y la atención, dominado por la desgracia (le malheur) que «se adueña del alma y la marca, hasta el fondo, con una marca que sólo a ella pertenece, la marca de la esclavitud $\rangle^{85}$. Sin embargo, es también punto de intersección entre la gracia divina y el mundo. El trabajo agotador nos permite tomar conciencia de la desgracia y de la miseria, introduciéndonos el universo en el cuerpo, en nuestro desfallecimiento sometido a la implacable necesidad del mundo. Porque en el pensamiento weiliano todo conocimiento de la verdad pasa necesariamente por el camino de la desgracia. Ahora bien, dicho camino de desgracia nos enseña de forma implacable que la verdad no puede ser, en último término, creación nuestra. Allí donde el trabajo acaba con nuestras fuerzas y aniquila nuestro espíritu, nos hace inevitablemente tomar conciencia, afirmará Weil, de que «el bien real no puede venir más que de fuera, nunca de nuestro trabajo» ${ }^{86}$. Si éste último es lugar de agotamiento y muerte en la filosofía weiliana -siempre contradictoria, siempre en tensión- es también lugar de salvación por la gracia, elemento sobrenatural destinado a aparecer en ese mismo instante de desfallecimiento extremo cuando todo está perdido: "sólo tras una larga y estéril tensión que acaba en desesperación, una vez que ya no hay nada que esperar, es cuando de fuera, oh maravillosa sorpresa, viene el don ${ }^{87}$. Porque, como escribió el poeta español Claudio Rodriguez: «Siempre la claridad viene del cielo; / es un don: no se halla entre las cosas / sino muy por encima, y las ocupa / haciendo de ello vida y labor propias» ${ }^{88}$.

Escribió Carlos Ortega que la filosofía de Simone Weil «descubrió un nuevo alfabeto, cruzado de desgracia y de belleza, de nostalgia y de

84. Weil, S.: Escritos cit., p. 165.

85. Weil, S.: L'enracinament cit., p. 75.

86. Weil, S.: La gravedad cit., p. 92.

87. Idem.

88. Rodriguez, C.: «Don de la ebriedad» en Hacia el canto. Salamanca: Ediciones Universidad de Salamanca, 1993, p. 43.

Thémata. Revista de Filosofía $\mathrm{N}^{\circ} 54$ (2016) pp.: 11-32 
perfección, de dolor y de alegría, para leer y pensar el mundo» ${ }^{89}$, repensar el poder de las palabras es el reto que nos deja su obra. Pero es el suyo un alfabeto de trágico destino, cuya más alta conquista es la revelación de su propia impotencia, de su inevitable imperfección para dar cuenta de la realidad. Porque sólo la gracia es portadora de verdad última. «El espíritu de la verdad está hoy casi ausente de la religión y de toda la ciencia» ${ }^{90}$, sostiene Weil, entonces la suprema exigencia de su obra, y de su vida misma, es una reforma radical de todos los ámbitos pensamiento y de las condiciones de vida de todo ser humano: la lucha hasta la extenuación por la reconciliación de todos los saberes y de todas las dimensiones de la vida bajo la luz de la verdad, esa luz de amor puro que se manifiesta como el esplendor de la realidad. Porque el pensamiento de Simone Weil, como ha destacado Roberto Esposito -quien sin duda es uno de sus más agudos lectores en la actualidad-, "es un pensamiento guerrero incluso cuando combate por la paz ${ }^{91}$.

Pero esta lucha sólo tiene sentido si es una lucha por la vida, para recuperarla de las fuerzas que la avasallan, para devolverla a la senda de la verdad, de la belleza, de la justicia. Precisamente este posicionamiento, que la llevó por un camino de compromiso humano y de entrega fuera de lo comunes, también la alejó muy pronto de la Revolución Soviética y de toda forma de totalitarismo. Porque, como ella misma afirmó, en un breve texto de 1933, escrito a propósito de la obra La condition humaine de André Malraux y de una reseña escrita por Bataille:

No se puede ser un revolucionario si no se ama la vida [...]. La revolución es una lucha contra todo aquello que constituye un obstáculo para la vida. Ella sólo tiene sentido como medio; si el fin perseguido es vano, el medio pierde su valor. En general, nada tiene valor desde el momento en que la vida humana no lo tiene. ${ }^{92}$

89. Ortega, C.: «La hermosura del mundo en Simone Weil» en Anthropos 211, 2006, p. 142.

90. Weil, S.: L'enracinement cit., p. 328.

91. Esposito, R.: «Simone Weil y Europa» en Archipiélago 43, 2000, Sep-Oct, p. 39.

92. Weil, S.: «À propos de La condition humaine de Malraux» en Euvres complètes. Tome II. Écrits Historiques et Politiques. Volume 1. L'engagement syndical (1927 - Juillet 1934). Paris: Gallimard, 1988, p. 318 
